\title{
Three cases of severely disseminated Staphylococcus aureus infection in patients treated with tocilizumab
}

\author{
Mai TT Nguyen, ${ }^{1}$ Jan Pødenphant, ${ }^{2}$ Pernille Ravn ${ }^{3}$
}

${ }^{1}$ Department of Infectious Diseases, University Hospital, Odense, Denmark ${ }^{2}$ Department of Rheumatology, University Hospital, Gentofte, Denmark ${ }^{3}$ Department of Infectious Diseases, University Hospital, Hillerød, Denmark

Correspondence to Pernille Ravn, peravn@gmail.com
To cite: Nguyen MTT, Pødenphant J, Ravn P. BMJ Case Reports Published online: 2 January 2013 doi:10.1136/bcr-2012007413

\section{SUMMARY}

We report three cases of severe disseminated Staphylococcus aureus infection in patients with rheumatoid arthritis (RA) treated with tocilizumab. Tocilizumab is a new drug, unknown to most internists, and injections given weeks before admission may not be considered by the patient as part of their 'current medical treatment', and the physician may not be aware that the patient is severely immunosuppressed. Severe infections in RA patients treated with tocilizumab may present with mild symptoms despite severe and disseminated infection and, as these patients are severely immunodeficient-intensive diagnostic work-up and early treatment should be performed. Systematic postmarketing studies are needed to clarify if there is a true increased risk of disseminated $S$ aureus infections. We suggest caution when prescribing tocilizumab to patients with prosthetic joints and/or prior invasive $S$ aureus infections and that patients are taught to inform health staff about their medication history and their increased risk of infection.

\section{BACKGROUND}

Severe infections in rheumatoid arthritis (RA) patients treated with tocilizumab may present with mild symptoms despite severe and disseminated infection and intensive diagnostic work-up, and early treatment should be performed. The patients and the physician may not be aware of the severity of immunodeficiency.

We suggest caution when prescribing tocilizumab to patients with prosthetic joints and/or prior invasive Staphylococcus aureus infections. We argue for systematic postmarketing studies to clarify if there is a true increased risk of disseminated $S$ aureus infection.

\section{CASE PRESENTATION \\ Background}

In 2008, the interleukin 6 (IL-6) inhibitor, tocilizumab, was introduced to treat patients with RA who do not respond to treatment with diseasemodifying antirheumatic drugs (DMARDS) or other biological treatment. IL-6 plays a key role in eliciting an acute phase response by inducing production of $\mathrm{C}$ reactive protein (CRP), differentiation of B-cells to antibody-producing cells, differentiation of cytotoxic T cells, leucocytosis and thrombocytosis. ${ }^{1} \mathrm{~A}$ marginally increased risk of infection compared with DMARD has been observed. ${ }^{2-4}$

Within the year 2011, we have seen three patients treated with tocilizumab who developed severe disseminated $S$ aureus bacteremia in Denmark and we report the cases here.

\section{Case 1}

A 68-year-old woman, receiving tocilizumab and methotrexate (figure 1A) for her RA, was admitted with progressive global weakness, mild confusion, aphasia and neck stiffness, but no fever. She had a history of severe RA for 35 years with previous joint replacement of the right elbow, left hip and both knees. On suspicion of neurological infection, lumbar puncture was performed. The cerebrospinal fluid was purulent and grew $S$ aureus. The blood culture was negative. MRI showed a massive epidural abscess from $\mathrm{C} 2$ to the sacrum and, in addition, a positron emission tomography (PET)-CT scan showed pathological activity around the prosthesis of the left hip. Immunosuppressive drugs were stopped and treatment was initiated with cefuroxime for a total of 6 weeks followed by oral dicloxacillin $1 \mathrm{~g}$ four times a day for 8 weeks and the infected hip prosthesis was removed. Despite this, she relapsed twice over the next 6 months and PET-CT was repeated which now revealed activity in the right elbow. She had clinical symptoms in both the knees and aspirate was performed from these joints which revealed $S$ aureus. All three prostheses were removed and she is now receiving longterm antibiotic treatment and has not relapsed.

\section{Case 2}

A 63-year-old man with type 2 diabetes and RA, receiving azathioprine and tocilizumab (figure $1 \mathrm{~B}$ ) had a 1-day history of chest pain and increasing pain in his left ankle. He had prostheses in both knees inserted 3 years prior to admission. On admission he had fever and swelling of the ankle. On suspicion of septic arthritis aspiration from the ankle joint was performed and gentamicin and cefuroxime were initiated. Shortly after, the left elbow, both knees, the right wrist and the basal joint of the left thumb were tender with swelling. Multiple aspirations were conducted and $S$ aureus was cultured from both knees, the left elbow joint and several blood cultures. Antibiotic treatment was changed to dicloxacillin and rifampicin after the growth of $S$ aureus. He was admitted for a total of 7 months with a need for aggressive surgical debridement. He had a history of $S$ aureus infection in the elbow $>3$ years prior to admission.

\section{Case 3}

A 59-year-old man with RA receiving methotrexate, prednisolone and tocilizumab (figure 1C) was admitted with 1 week of fever, cough and dyspnoea. Blood cultures were positive for $S$ aureus and he was treated with intravenous dicloxacillin $1 \mathrm{~g}$ four times a day. A pleural effusion developed and $S$ aureus was grown from a diagnostic aspirate 
(a)

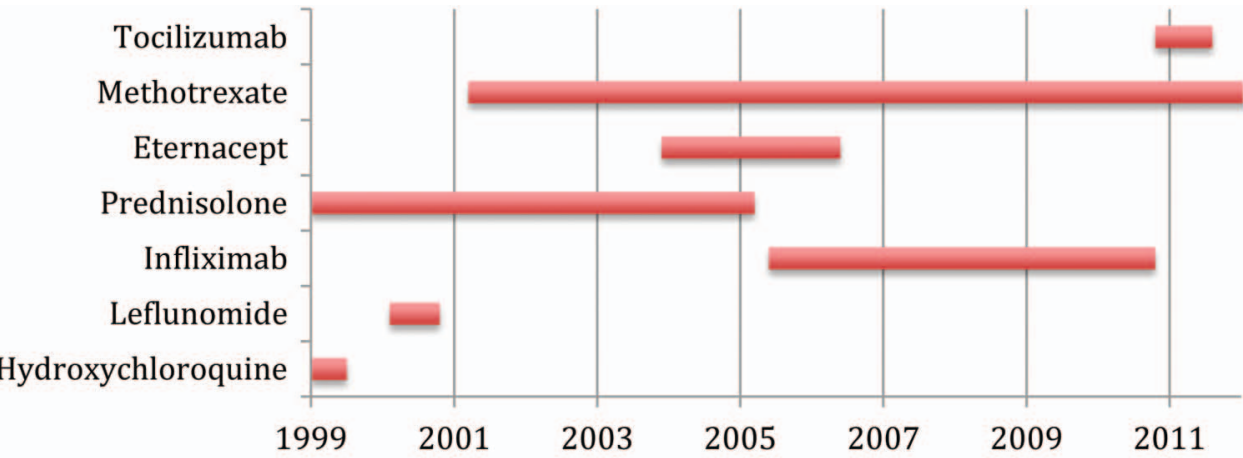

(b)

(c)
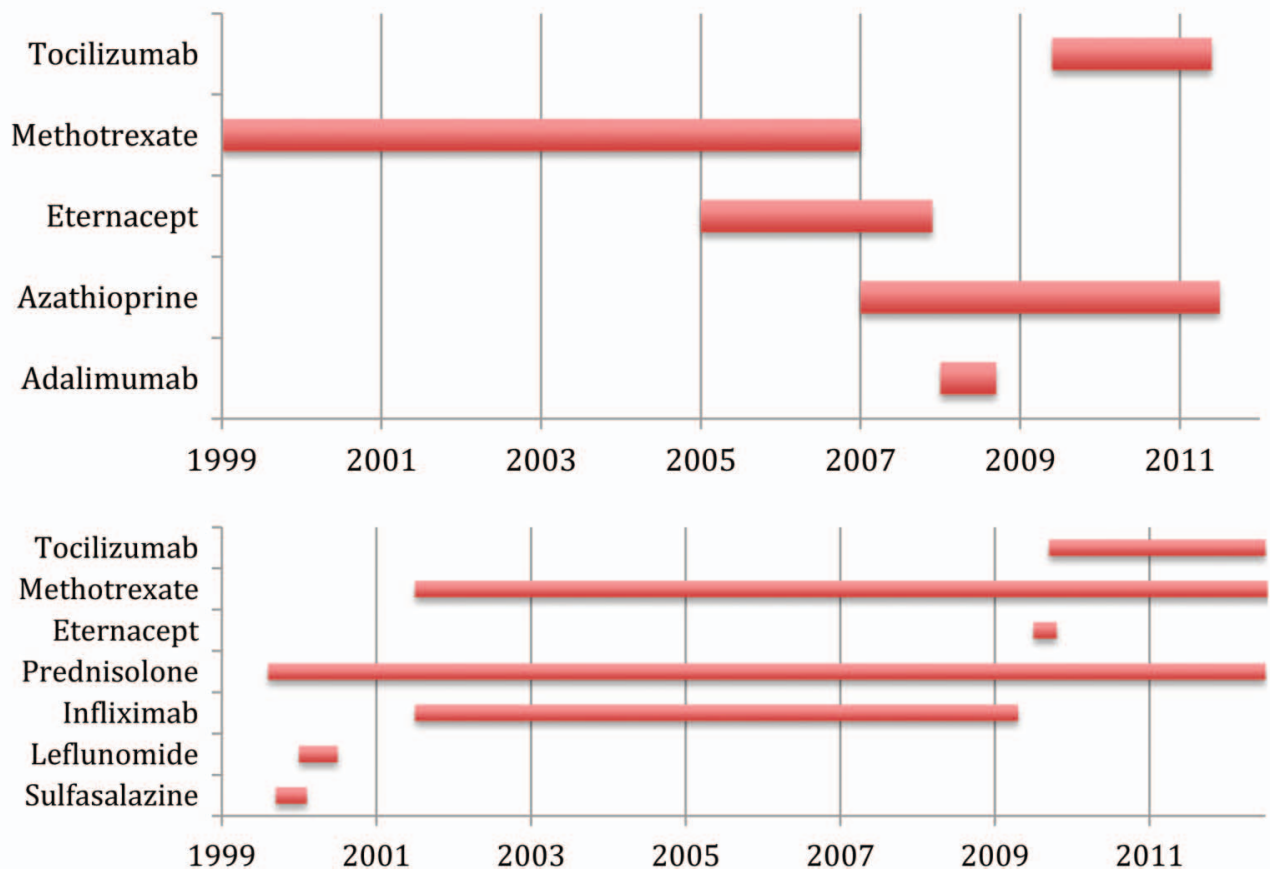

Figure 1 (A-C) Medical history of three patients who developed severe Staphylococcus aureus infection during treatment with tocilizumab.

despite 1 week of relevant treatment. The situation was complicated by respiratory failure, myocardial infarction and disseminated intravascular coagulation, and he died 11 days after admission. One year before, he had been treated for infection with $S$ aureus in his olecranon bursa. In all three cases, endocarditis was excluded by transoesophageal ECG.

\section{DISCUSSION}

We have reported three cases of severe $S$ aureus infection in RA patients treated with tocilizumab of whom one died and the other two were hospitalised for $>4$ months. All had advanced RA and a long treatment history and two patients had a history of prior invasive $S$ aureus infection and two had prosthetic joints.

All three cases had relevant symptoms for the doctor to suspect an infection and initiate early treatment and appropriate diagnostic investigations. The CRP was relatively low (table 1 ) and it was possible for the patients to make an inflammatory response, although the CRP seemed low compared with the extent and severity of infection.

It was not registered in any of the admissions file that the patients had received tocilizumab injections 1-4 weeks prior to admission. Tocilizumab is a new drug, unknown to most internists, and injections given weeks before admission may not be considered by the patient as part of the 'current medical treatment' and may not be registered properly by the physician.

Not removing prosthetic joints is a strong predictor for relapse. ${ }^{5}$ Whether immediate removal of all prosthetic joints in case 1 might have changed the duration of illness is unknown.

No information on $S$ aureus colonisation of the skin was available, and it is unknown whether de-colonisation would be able to prevent infection in these patients.

In Denmark, 158 patients received tocilizumab in 2011 (http://www.danbio.dk), and three cases of $S$ aureus infection

Table 1 Laboratory values on admission

\begin{tabular}{lllll}
\hline & Case 1 & Case 2 & Case 3 & Reference values \\
\hline CRP & 14 & 45 & 36 & $\mathrm{mg} / \mathrm{l}$ \\
Total leucocyte count & 20.3 & 13 & 7.6 & $10^{9} / \mathrm{l}$ \\
Neutrophil leucocyte count & 14.6 & $\mathrm{nd}$ & 6.76 & $10^{9} / \mathrm{l}$ \\
Lymphocyte count & 0.2 & $\mathrm{nd}$ & 0.53 & $10^{9} / \mathrm{l}$ \\
Haemoglobin & 9.3 & 6.3 & 8.5 & $\mathrm{Mmol} / \mathrm{l}$ \\
Albumin & 44 & 20 & 37 & $\mathrm{~g} / \mathrm{l}$ \\
Thrombocytes & 152 & 171 & 88 & $10^{9} / \mathrm{l}$ \\
\hline CRP, C reactive protein. & & & &
\end{tabular}


reflect a high incidence, but systematic postmarketing studies should clarify if there is a true increased risk of $S$ aureus infections.

We suggest caution when prescribing tocilizumab to patients with prosthetic joints and/or prior invasive $S$ aureus infections. All patients should be aware that they should inform health staff about their medication history and their increased risk of infection.

\section{Learning points}

- Patients treated with biological antibodies should be considered severely immunocompromised and treated as such with intensive diagnostic work-up and immediate antibiotic treatment if infection is suspected, as severe infection may present in a less florid manner.

- Prior Staphylococcus aureus infections may be a risk factor for $S$ aureus infection.

- Removal or debridement of infected prosthesis is essential if eradication of infection is to be achieved.

- Postmarketing surveillance is important to increase the level of evidence regarding an increased risk of severe or disseminated infections with $S$ aureus following treatment with tocilizumab.
Competing interests None.

Patient consent Obtained.

Provenance and peer review Not commissioned; externally peer reviewed.

\section{REFERENCES}

1 Nishimoto N, Kishimoto T. Interleukin 6: from bench to bedside. Nat Clin Pract Rheumatol 2006;2:619-26.

2 Schiff MH, Kremer JM, Jahreis $A$, et al. Integrated safety in tocilizumab clinical trials. Arthritis Res Ther 2011;13:R141.

3 van de Sande MG, van Slobbe-Biilsma ER. Necrotizing fasciitis in a rheumatoid arthritis patient treated with tocilizumab 1. Rheumatology (Oxford) 2012;51:577-8.

4 Hoshi D, Nakajima A, Inoue E, et al. Incidence of serious respiratory infections in patients with rheumatoid arthritis treated with tocilizumab 2. Mod Rheumatol 2012;22:122-7.

5 Thwaites GE, Edgeworth JD, Gkrania-Klotsas E, et al. Clinical management of Staphylococcus aureus bacteraemia. Lancet Infect Dis 2011;11:208-22.

Copyright 2013 BMJ Publishing Group. All rights reserved. For permission to reuse any of this content visit http://group.bmj.com/group/rights-licensing/permissions.

BMJ Case Report Fellows may re-use this article for personal use and teaching without any further permission.

Become a Fellow of BMJ Case Reports today and you can:

- Submit as many cases as you like

- Enjoy fast sympathetic peer review and rapid publication of accepted articles

- Access all the published articles

- Re-use any of the published material for personal use and teaching without further permission

For information on Institutional Fellowships contact consortiasales@bmjgroup.com

Visit casereports.bmj.com for more articles like this and to become a Fellow 